\title{
COMPUTER-BASED INTEGRATED BUSINESS PLANNING ON THE BASIS OF BUSINESS MODEL DEFINITION
}

\author{
Yuliya Vykhodets ${ }^{1}$, Igor Chumachenko ${ }^{2}$ \\ ${ }^{1}$ National Aerospace University “Kharkov Aviation Institute”, Ukraine, yu.vykhodets@khai.edu \\ ${ }^{2}$ National Aerospace University "Kharkov Aviation Institute”, Ukraine, ivchum@mail.ru \\ cross $^{\text {ref }}$ http://dx.doi.org/10.5755/j01.em.17.1.2298
}

\begin{abstract}
The article is devoted to the integrated business planning for the cases of business establishment, expansion or transformation under different scenarios. The practical basis for the presented generalizations consists of lessons learned through implementing 14 projects for 10 Ukrainian enterprises and organizations. The theoretical basis covers business economics, strategic and financial management, business systems design, project management, business informatics. The process of coherent and affordable business plan development is considered. The authors operate with the term "business model", as a set of roles and relationships, which are carried by the entity to get profit and positive cash flow within a certain structure of interests. The authors' approach to the integrated business planning is described and grounded. It is necessary to distinguish modelling of the company activities and modelling for a business model. If the company operates several business models (like manufacturing and trade) then each business model requires a separate computer model.

Keywords: ICEM 2012, business model, integrated business planning, cash flow modelling, computer modelling of business development scenarios.

JEL Classification: M21.
\end{abstract}

\section{Introduction}

Purpose of the article is to deliver practical findings and generalizations, which may help to improve the reliability and validity of computer models for middle-term integrated business planning (2-3 years). Small and medium enterprises have been considered (manufacturers of milk products, meat products, office furniture, polymer concrete items for interior etc.). The paper addresses to the general problem of ensuring business growth and business continuity. Motivation to expand the business without attention to the current business model may lead to destructive consequence. Resulting portfolio of business models may be non-coherent. For example, if a food manufacturer has a local retail network, this may prevent him from increasing of sales through other distribution channels within the region of location. Thus, a possibility of growth is under the question, and the owner has to decide what the core business is: manufacturing or retailing.

The paper concerns cases when the company owner directly participates in management activities (for example, holds a top-management position or participates in decision making being a member of a relevant committee). In the middle-term perspective the company owner may consider following alternatives:

- to develop the business, to ensure its growth, to increase operation effectiveness, and to secure control;

- to prepare for the business selling.

The performance targets will differ for above mentioned alternatives. Zones of the special attention will differ too. Thus, goals set for the top-management depend on the owner's intentions with regard to the business. This paper focuses on the rational organization of building an achievable business plan for the first case. It is anticipated that the top management team will have to build a medium-term business plan and to ensure the continuity and viability of the business model. The second alternative is not considered in this study.

So the owner has decided to develop the business. The next step is to form a system of goals for the top management. The goals should be specific, measurable, agreed, ambitious, but achievable, realistic, timebound. Goals, which are not affordable, demotivate the top managers and the company staff. Therefore, at least the key owners and top managers must participate in the process of setting goals, analyzing limitations and searching relevant action scenarios. We emphasize: the owners of small and medium-size businesses in Ukraine often participate in processes of business administration. Being in two roles at once (as an owner and a top-manager), they try to take into account the opinion of the management team with respect to the goals' affordability. Despite their frequent desire to move away from the company's management, they demonstrate high level of responsibility for the operations and viability of the company. Accordingly, we observe that the owners are interested in organizing the integrated business planning, which would take into consideration their goals and interests along with capabilities and limitations of the top management.

Let's assume that the company's executives and owners are motivated to ensure the business growth and secure the business viability. The general problem may be stated as follows: to find a coherent model of 
goals and build an appropriate business plan by means of integrating efforts and information from owners and top management. Here we distinguish the two main practical problems, which should be solved: to ensure parties' motivation and to organize communications. The local modelling task is to construct a flexible electronic searching model in order to determine realistic and achievable combination of goals and manageable business parameters. Thus, described approach was applied for creating coherent procedures and modelling tools. Advantages of the combined efforts in the integrated business planning are obvious: 1) all the parties involved see the sources of the operational, financial and investment decisions; 2) every participant sees and understands how the combination of these decisions is effective, realistic and affordable; the participants make judgements based on their own work context and communicate to each other.

Methodology. The practical basis for the presented generalizations consists of lessons learned through implementing 14 projects for 10 Ukrainian enterprises and organizations. One of the authors took part in all the projects as an external consultant or a project team member. The projects were initiated by the owners and were positioned as business development projects. In fact, 5 projects were rejected after the feasibility study phase. The tasks itself required to build a simulation tool in order to check compatibility of investment and financing plans with the operating activity.

Generalized questions from the owners were the following: 1) what part of the business diversification/integration project expenses may be financed from the current operating income; 2) how certain financing sources affect the business and its viability; 3) what maximum affordable growth is feasible for the company with current facilities; 4) what production output should be planned for the new business; 5) when the company will be able to finance the equipment modernization; 6) how to inspire top-managers to ambitious but prudent business plans; 7) possible profit and cash flow under the current conditions and most probable changes. These different issues required to describe the current business model and to organise a platform for joint modelling of changes by the key decision makers.

The last project (2010) was already positioned as organizing the middle-term business planning through effective collaboration procedures between owners and top-managers in order to ensure both business growth and viability.

The theoretical basis covers following scopes of knowledge: business economics, strategic and financial management, business systems design, project management. The practical application requires a tool for scenario planning and here we address to the work of Schoemaker (1995). The most relevant publication according to the business model definition and classification is the MIT study of business models (Maloni et al., 2006). Klang, Wallnöfer \& Hacklin (2010), Linder \& Cantrell (2000), Osterwalder \& Pigneur (2004), Ostenwalder, Pigneur \& Tucci (2005) have provided in-depth studies of business model ontology, typology, definitions, impact of the business model on corporate information systems and distinctions between business model and enterprise model, business process model. Review of open sources, available in English and Russian language has shown that application of the business model concept for computer-based integrated business planning is not well elaborated and discussed. Osterwalder and Pigneur (2004) define strengths of the business model concept and include "the ability to create a transparent big picture of a business and to externalize the relationships and dependencies of the business elements".

\section{Description of the modelling tool}

The project teams had to create a computer model for middle-term business planning. Business owners or top managers were the end-users. The model was to help its users in the following:

1) to test various scenarios of growth / expansion / transformation (profits and cash flow, risks, sensitivity);

2) to find such values of inputs (managed business parameters) those allow achieving the desired financial results.

The logic of the model building and its further use is shown on the Figure 1. The models of growth and resource inputs are the basis for calculating production volume, revenue and cost estimates.

The cash flow depends on the production output and payment/delivery conditions applied to suppliers and clients. The activity of the previous and subsequent periods affects on the cash flow of the current period. Thus we obtain a model of operating income, expenses, and cash flow.

This model provides an insight into the operations of the business. In fact, it is description of the current business model. Then the operating model is added with non-operating plans (investment and financial plans reflecting prospective projects and plans for entering new businesses). The result is an integrated model of income, expenses and cash flow. Other important controlled indicators may be added 
too, if the model allows. The modelling output shows the resulting indicators. The model users decide how acceptable are the plans introduced under the given conditions.

\begin{tabular}{|c|c|c|c|c|}
\hline $\begin{array}{c}\text { Basic production } \\
\text { volume } \begin{array}{c}\text { BTATISTICS } \\
\text { STATISTICS }\end{array}\end{array}$ & $\begin{array}{c}\text { Sales growth, } \% \\
\text { INPUT }\end{array}$ & $\begin{array}{c}\text { Price growth, } \\
\text { INPUT }\end{array}$ & $\begin{array}{c}\text { Calculated } \\
\text { production } \\
\text { volume }\end{array}$ & Calculated income \\
\hline List of resources STATISTICS & $\begin{array}{c}\text { Resource consumption norms } \\
\text { STATISTICS }\end{array}$ & Calculated resources \\
\hline \\
\hline
\end{tabular}

Figure 1. The modelling logic

Following assumptions were applied:

- Assumption about the business model constancy. The model is based on statistical data and resource consumption model. So, it is intended for checking decisions which do not lead to business model change. We define business model as a set of roles and relationships, which are carried by the entity to get profit and positive cash flow within a certain structure of interests. The given assumption is essential. A scenario may anticipate some changes in the business model and can show its financial and economic affordability and expediency. However, in practice it can appear not viable as the company has not the proper structure and processes. The business model creates requirements and limitations for the sourcing strategy, pricing policy, resource consumption, terms of payment/delivery etc. So, each considered business model requires separate modelling of incomes, resource consumption and cash flow. Investment decisions which do not influence business model change: production facilities replacement/ modernization; expansion of capacities; reconstruction of buildings.This assumption is a basis of the whole modelling process, because the operating income sources and the cost drivers depend on a complex of roles and communications which are incurred by the company in the given direction of activity. Thereupon the first and main step is to define the set of maintained business models. Working as an agent and as a distributor are different business models. The parity of direct and indirect expenses, drivers of expenses, model of calculation of expenses and risks will be different for these two roles. Therefore each business model should be reflected in the simulation tool. Identifying the business model is a separate scientific and practical problem. The MIT study of business models (Maloni et al., 2006) gives a good insight into the problem. Identification of the business model change is essential for business planning, especially when several scenarios are considered. Linder and Cantrell (2000) in their working paper propose four basic types of change models: realization models, renewal models, extension models, and journey models. Change models may help in generating scenarios of business development and identification of time boundaries for each business model considered.

- Assumption about constancy of BOM and manufacturing technique during a planning interval. The subjects for consideration are the planning period (horizon), fiscal year and the planning intervals. The majority of the model users prefer monthly planning. But experience acquired from the food 
industry shows that recipes and resource cost along with internal processes may change according to agricultural seasons and availability of the core resources. If so, it may be more expedient to divide the planning horizon into another time intervals which are more suitable to operate with BOMs, recipes and prices for the core resources. Using a month as a planning interval is common, but creates limitations. Search and choice of an optimum manufacturing technique and recipe are not considered here, as it is more related to operational planning, technological improvement and quality management.

- Assumption about equality between manufacture and shipments within a planning interval. Simulation of stock movement was not introduced.

- Assumption about constancy of terms and conditions of payment/delivery within a time interval. The model of cash outflow was based on the financial behaviour of suppliers and was introduced for every resource. Modelling of operating cash inflow required certain statistics and information about the contract conditions in past and future.

Limitations of the model:

- Only a limited quantity of alternative BOMs may be introduced into the model.

- Current business model can be not optimum itself.

- The company may not have transparent and reasonable practice of budgeting expenses (for example, business trips and transportation of raw materials). This may complicate the process of building resource consumption model and data validity is called in question.

- The context of our projects allowed us to neglect necessity of creating stocks. Although we understand that this is not acceptable for some industries and business models.

Examples of the users' inquiries for upgrading the model:

- Adding a new product/ resource/ BOM / recipe.

- Change in terms of payment/ delivery (for clients or suppliers).

- Change of a resource quantity calculation method, change of a resource price forecasting method.

- Addition/removal of target performance indicators.

- Change of an accounting or depreciation policy.

The models have been created in the spreadsheet (MS Excel). The marginal approach has been implemented and relevant models of income, expenses and cash flow were structured and built. The target performance indicators are:

- Cash flow (a function from the sales, operating costs, payment terms with suppliers and customers, cash inflow and outflow from investing and financing activities).

- Operating income (a function from the basic sales volume, the basic price, the simulated increase in sales volume, the simulated price increase).

- Operating cost (a function from amount of resources, prices for resources).

Depending on the business model, each argument (input) may be presented as a function or variable. The model developer has to obtain set of variables (inputs) that characterize the business. We assign each item to one of the following groups:

- Group 1 includes manageable variables. The input data is an information about intentions to act with certain parameters.

- Group 2 includes unmanageable variables with possibility to predict values. The input data contains expected values of unmanageable parameters.

- Group 3 includes unmanageable variables without possibility to predict values with the necessary degree of certainty. The input data contains conditions of work and environment status. The aim is not to forecast the values, but to make "what-if" analysis for different variants.

So, the content of modelling consists of "what-if" analysis for different values of the variables of group 3 and searching matching values in group 1 ("what has to be done").

\section{Description of the model usage process}

Some elements of using similar approach (key roles and responsibilities, procedures of data preparation and input) have been discussed and described by the authors in the research report devoted to project management in machinery manufacturing (Chumachenko et al., 2010).

Here we provide revised and adopted vision of functions, roles and responsibilities according to the procedure of business modelling and cases, which are covered here. So, the set of actions connected to the 
model use can be divided into 3 groups:

- Generating scenarios and solutions. This may include ideas about needed changes, resource consumption norms, payment and delivery terms, sales volume, prices, growth of sales and the prices, investment and financial plans, the scenario acceptability analysis. The main role is to identify probable scenario and develop a response to change of an uncontrollable parameter, if it leads to an undesirable outcome. Mentioned actions require forming a business modelling team which may consist of the owner, operating director and chief officers (production, sales, finance, accounting, and other officials if needed).

- Information delivery and analysis. This includes keeping and processing corporate statistics, construction of an adequate resource model which reflects the current business model. Expectations from the staff members involved in this activity are following: to reveal, formalize and review dependences. Sometimes it is necessary to choose the proper method of calculating resource input. For example, it may be grounded that the cost of fuel is a function from the sales volume, cost of raw materials and staff number. It may be necessary to gather the fact sheet about use of resources and to analyze dependence between their consumption and production volume, quantity and cost of raw materials, operating income and other factors. The given functions may be carried out by the Chief economist, financial department and officials who are responsible for the development and performance of the corresponding budgets.

- Technical implementation (data input, updating formulas, report preparation, managing versions of model). These actions require appointing an operator of the model.

Thus, it is necessary to identify the following candidates: leader-coordinator, business modelling team members, information support team members, technical assistant (operator).

Having the model built according to the above mentioned logic, the business modelling team (working group) obtains a modelling instrument. Further success or failure of the modelling process depends on reliability of input data and coordinated actions. Referring to own successful background we deliver here an example of the procedure (Figure 2).

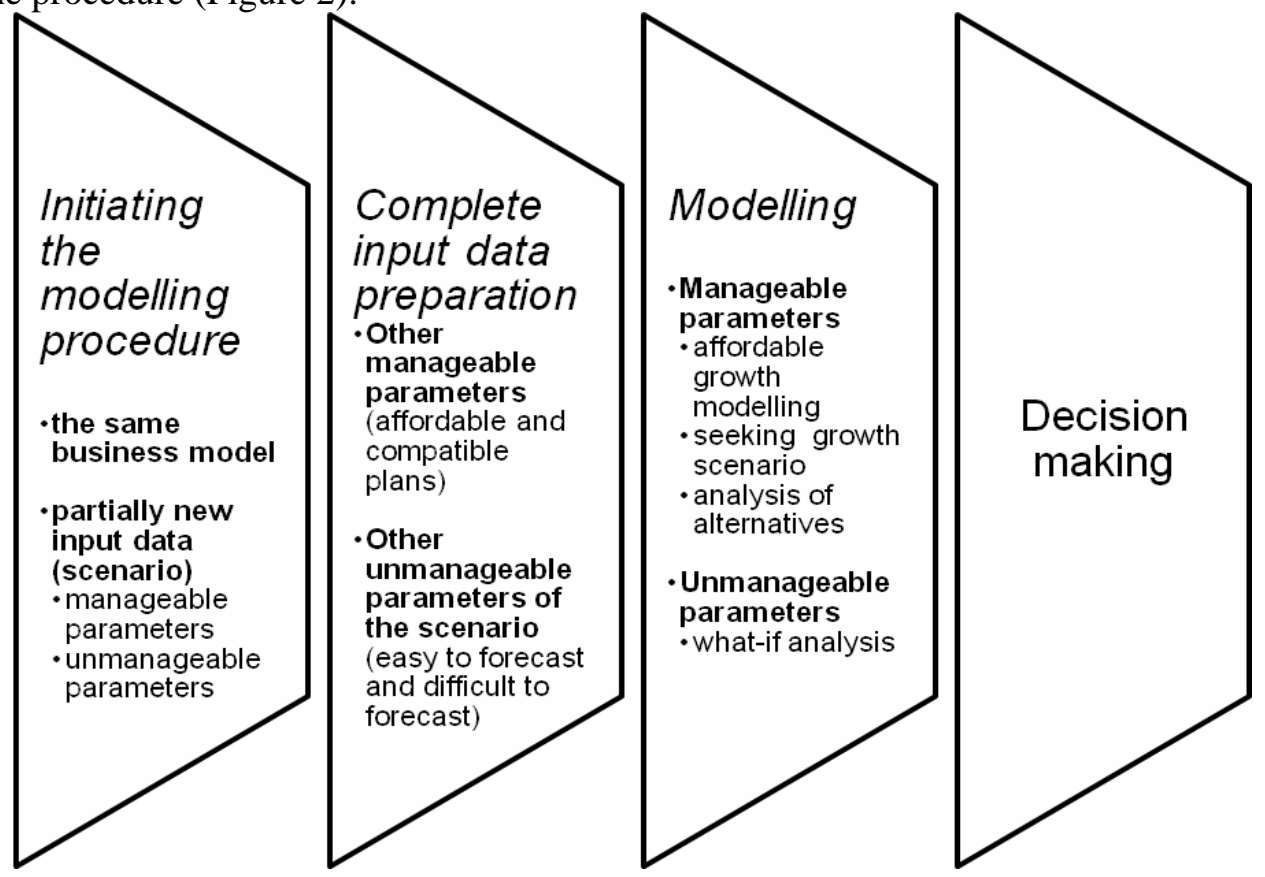

Figure 2. The general procedure scheme

The owner or other involved person initiates the modelling procedure with proposing a certain scenario. For example, they've got a proposal to produce their standard products under a private label and have to "try on" this contract. Another case: necessity to set pricing policy and to make "what-if" analysis regarding to currency exchange rates, prices for the core resources.

The leader-coordinator organises a meeting with the business modelling and information supply groups and gives the task to prepare the initial data corresponding to the considered scenario (table 1). 
Table 1. Example of responsibility distribution (Chumachenko et al., 2010)

\begin{tabular}{|l|l|}
\hline \multicolumn{1}{|c|}{ Data } & \multicolumn{1}{c|}{ Responsible officers } \\
\hline Volumes of production and sales & Sales manager \\
\hline The average sales prices (current and forecasted) & Sales manager \\
\hline $\begin{array}{l}\text { Data on investment activity (the plan of investments, } \\
\text { incomes and expenses on realization of the basic means) }\end{array}$ & $\begin{array}{l}\text { Business development manager / chief technology } \\
\text { officer/owner }\end{array}$ \\
\hline $\begin{array}{l}\text { Data on financial activity (available financing sources, } \\
\text { incomes and expenses, cash flow on financial activity) }\end{array}$ & Chief accountant /owner \\
\hline Basic raw materials' prices and their trends & Supply manager, sales manager, marketing director \\
\hline Resource model (resource consumption forecast) & Chief economist \\
\hline Depreciation & Chief economist \\
\hline New products introduction plan & $\begin{array}{l}\text { Chief economist / sales manager / chief technology } \\
\text { officer }\end{array}$ \\
\hline Taxes, inflation forecast & Chief accountant \\
\hline
\end{tabular}

The responsible persons prepare required data and pass it to the technical assistant (operator) by means of exchange forms. Then the operator creates a model version for the considered scenario and enters the obtained data. The created version of the model is to be transferred to the leader-coordinator.

The leader organizes a meeting of the working group for joint decision making as to acceptability of the considered scenario. If the model gives an adverse forecast of performance indicators, the working group may generate and consider some alternatives. The working group approves certain acceptable scenarios as alternatives of the business plan. Considerations may include the following:

- Possibility and needed arrangements to increase the sales price.

- Change in production plan.

- Alternative bills of materials (BOM) for certain products, alternative manufacturing technique.

- Alternative sourcing of materials and financing.

- Postponing or revising the investment plan.

- Possibility to change the terms of payment/delivery.

\section{Conclusions}

The business model concept becomes more and more interesting for enterprise owners and topmanagement of small and medium businesses. In this paper we have made an attempt to describe our own experience of its practical application, which was driven by necessity to compare different scenarios and build an affordable and viable business plan. Our propositions concerning use of the business model concept for business planning are following:

- it is necessary to distinguish modelling of the entire company activities and simulation for a separate business model. Each business model (current or future) requires a separate simulation tool. Different scenarios may anticipate different business models and therefore may require different simulation tools as well.

- The process of integrated intermediate business planning provides three levels of participation: 1) creating scenarios and decision making; 2) organization of necessary accounting and data gathering, search of dependences; 3 ) technical operation (data acquisition and input).

- If it is anticipated to switch from one business model to another during the planning horizon, the temporal boundaries for each one should be defined.

- Differences between business models may be reflected in the simulation tools in the following ways:

- Shifting the variables from one group to another (manageable variable may become unmanageable). Examples: payment terms and conditions, product prices.

- Changing patterns used to forecast the values of variables.

Described simulation tool, key assumptions, and communication procedures compose an approach to ensure collaboration between company owners and top management. The novelty of the presented approach lays in suggestion that the business model should be considered as a "unit of modelling". Considered combination and consequence of business models define needed configuration of the simulation tool. Thus, 
vision of the corporate business model(s) evolution process (direction and dynamics of changes) becomes a part of business development scenario and impacts processes of setting goals.

\section{References}

1. Chumachenko, I., Vykhodets, Y., Sorokina, I., Bugas, D., Dotsenko, N., Lysenko, A,..., Ugol'nikov, V. (2010). Methodological support for preparation and management of the complex projects of enterprise development in the machine building and transport industries(in Russian). Technical report (final) D602-30/2009, DR № 0108U011072, inv. № 0210U004410. Ukraine, Kharkov: National Aerospace University "Kharkov Aviation Institute'.

2. Klang, D., Wallnöfer, M., Hacklin, F. (2010). The anatomy of the business model: a syntactical review and research agenda. DRUID Summer Conference 2010 "Opening Up Innovation: Strategy, Organization and Technology". UK: Imperial College London Business School, June 16-18, 2010

3. Linder, J., Cantrell, S. (2000). Changing Business Models: Surveying the Landscape. Working Paper. Accenture Institute for Strategic Change.

4. Malone, T.W., Weill, P., Lai, R.K., D’Urso, V.T., Herman, G., Apel, T.G., Woerner, S.L. (2006). Do Some Business Models Perform Better Than Others? Working paper 4615-06. Cambridge, Massachusetts: MIT Sloan School of Management. Retrieved from http://seeit.mit.edu/Publications/ BusinessModelsPerformance12July2006.pdf.

5. Osterwalder, A., Pigneur, Y. (2004). Investigating the Use of the Business Model Concept through Interviews. ICEB'2004. Switzerland: HEC Business School, University of Lausanne. Retrieved from http://www.hec.unil.ch/yp/pub/04-ICEB.pdf

6. Ostenwalder, A., Pigneur, Y., Tucci C.L., (2005). Clarifying Business Models: Origins, Present, and Future of the Concept. Communications of AIS, Volume 15, Article 12.

7. Schoemaker, P. J. H. (1995). Scenario Planning: A Tool for Strategic Thinking. Sloan Management Review, Vol. 36 (2), Winter 1995, pp. 25-40. 